\title{
Anti-inflammatory effects of Ciwujianoside C3, extracted from the leaves of Acanthopanax henryi (Oliv.) Harms, on LPS-stimulated RAW 264.7 cells
}

\author{
DA-HYE KANG ${ }^{1 *}$, OK-HWA KANG ${ }^{1 *}$, ZHI LI $^{2}$, SU-HYUN MUN ${ }^{3}$, YUN-SOO SEO ${ }^{1}$, \\ RYONG KONG $^{3}$, ZHOU TIAN ${ }^{1}$, XIANGQIAN LIU ${ }^{2}$ and DONG-YEUL KWON ${ }^{1}$
}

\author{
${ }^{1}$ Department of Oriental Pharmacy, College of Pharmacy and Wonkwang-Oriental Medicines Research Institute, \\ Institute of Biotechnology, Wonkwang University, Iksan, Jeonbuk 570-749, Republic of Korea; ${ }^{2}$ School of Pharmacy, \\ Hunan University of Chinese Medicine, Changsha, Hunan 410208, P.R. China; ${ }^{3}$ BK21 Plus Team, \\ College of Oriental Medicine, Professional Graduate School of Oriental Medicine, \\ Wonkwang University, Iksan, Jeonbuk 570-749, Republic of Korea
}

Received August 3, 2015; Accepted August 4, 2016

DOI: $10.3892 / \mathrm{mmr} .2016 .5710$

\begin{abstract}
The present study aimed to investigate the unknown mechanisms underlying the anti-inflammatory activity of Ciwujianoside C3 (CJS C3), extracted from the leaves of Acanthopanax henryi Harms, on lipopolysaccharide (LPS)-stimulated RAW 264.7 cells. Cells were treated with CJS C3 for $1 \mathrm{~h}$ prior to the addition of $200 \mathrm{ng} / \mathrm{ml} \mathrm{LPS}$. Cell viability was measured using the MTS assay. Nitric oxide levels were determined by Griess assay. Proinflammatory cytokine production was measured by enzyme-linked immunosorbent assay. The expression levels of cyclooxygenase (COX)-2, inducible nitric oxide synthase (iNOS), and mitogen-activated protein kinases (MAPKs) were investigated by western blotting, reverse transcription (RT)-polymerase chain reaction (PCR) and RT-quantitative PCR. Nuclear factor (NF)- $\kappa \mathrm{B} / \mathrm{p} 65$ localization, and interaction of the TLR4 receptor with LPS was examined by immunofluorescence assay. The results indicated that CJS C3 exhibited no cytotoxicity at the measured concentrations. Treatment with CJS C3 inhibited NO production, proinflammatory cytokine levels, including interleukin (IL)-6,
\end{abstract}

Correspondence to: Professor Dong-Yeul Kwon, Department of Oriental Pharmacy, College of Pharmacy and Wonkwang-Oriental Medicines Research Institute, Institute of Biotechnology, Wonkwang University, 460 Iksan-daero, Iksan, Jeonbuk 570-749, Republic of Korea

E-mail: sssimi@wku.ac.kr

Dr Xiangqian Liu, School of Pharmacy, Hunan University of Chinese Medicine, 1 Xiangzui, Changsha, Hunan 410208, P.R. China

E-mail:1xq0001cn@163.com

*Contributed equally

Key words: Ciwujianoside C3, Acanthopanax henryi (Oliv.) Harms, MAPKs, proinflammatory cytokines, TLR4, NF- $\mathrm{kB}$ tumor necrosis factor (TNF)- $\alpha$, and prostaglandin $\mathrm{E}_{2}\left(\mathrm{PGE}_{2}\right)$, and protein and mRNA expression levels of iNOS and COX-2. Furthermore, CJS C3 suppressed phosphorylation of extracellular signal-regulated kinases and c-jun $\mathrm{N}$-terminal kinases. It was also able to suppress activation of $N F-\kappa B$ via inhibition of the TLR4 signaling pathway. These results suggested that CJS C3 exerts inhibitory effects on LPS-induced $\mathrm{PGE}_{2}, \mathrm{NO}$, IL- 6 and TNF- $\alpha$ production. In addition, iNOS and COX-2 expression was decreased in murine macrophages. These inhibitory effects may be achieved via suppression of MAPKs and NF- $\kappa \mathrm{B}$ phosphorylation following inhibition of the TLR4 signaling pathway.

\section{Introduction}

Acanthopanax henryi (Oliv.) Harms belongs to the Araliaceae family, and may be used as a traditional Oriental medicine for the treatment of rheumatism and inflammation $(1,2)$. Phytochemical studies have identified lignans and other compounds in the bark of Acanthopanax henryi (Oliv.) Harms, including syringin, syringaresinol, diglucoside, octacosanoic acid and beta-sitosterol (3). Pharmacological studies have reported that the $\mathrm{MeOH}$ extract and fraction of the root bark of Acanthopanax henryi exerts anti-inflammatory and anticancer effects (3-5). At present, several studies have been conducted regarding the pharmacological effects of Acanthopanax henryi root bark; however, studies on the leaves of Acanthopanax henryi (Oliv.) Harms are few $(5,6)$. Therefore, the present study aimed to investigate the anti-inflammatory effects of Ciwujianoside C3 (CJS C3); full name, echinocystic acid 3-O- $\beta$-D-glucopyranosyl$(1 \rightarrow 3)-O-\alpha$-L-arabinopyranoside, isolated from the leaves of Acanthopanax henryi (Oliv.) Harms (Fig. 1).

Inflammation is a physiological response, and asthma, obesity and diabetes are common inflammatory diseases (7). Inflammatory responses induced by microbial infections stimulate the innate immune system against foreign components, including lipopolysaccharide (LPS) (8), which is a cell 
wall component of gram-negative bacteria that is detected by Toll-like receptor 4 (TLR4). Macrophages are able to bind to LPS to induce the activation of inflammatory signals and the release of proinflammatory cytokines, chemokines and mediators of the inflammatory response (9).

Nitric oxide (NO), also known as nitrogen monoxide, which is synthesized from L-arginine by nitric oxide synthase (NOS), regulates several physiological functions (10). The NO free radical produced by the inducible NOS (iNOS) isoform is an essential component of host innate immunity and the inflammatory response to various pathogens (11).

The biosynthesis of prostaglandins (PGs) is initialized by the cyclooxygenase (COX) isoenzymes, COX-1 and COX-2. COX-2 is an inducible isoform of COX that is present in inflammatory cells, which generally produces PGs associated with inflammation, fever and pain (12).

TLRs have important roles in the molecular mechanisms underlying inflammation (13), particularly TLR4, a protein that in humans is encoded by the TLR4 gene. TLR4 is able to detect LPS, and therefore has an important role in activation of the innate immune system $(14,15)$. It has previously been demonstrated that LPS-stimulated inflammation is predominantly mediated by TLR4 and cluster of differentiation 14 (16).

The extracellular-signal regulated protein kinases (ERK) pathway is able to phosphorylate various transcription factors upon activation, as well as two classes of mitogen-activated protein kinases (MAPKs): p38 MAPK and c-jun N-terminal kinases (JNK) (17). LPS stimulation of RAW 264.7 cells rapidly activates all of these MAPKs (18).

Nuclear factor (NF)- $\mathrm{kB}$ is involved in the cellular response to various stimuli, including stress, cytokines, free radicals, ultraviolet light, irradiation, oxidized LDL, and bacterial or viral antigens. NF- $\mathrm{kB}$ has a key role in regulating the immune response to infection, and is responsible for cytokine production and cell survival (19-23).

The present study aimed to determine the mechanisms underlying the anti-inflammatory effects of CJS C3; therefore, its effects on LPS and TLR4 binding, and on the production of proinflammatory mediators and cytokines were investigated. The present study confirmed that the MAPK and NF- $\kappa B$ signaling pathways were activated in RAW 264.7 macrophages that had been treated with LPS.

\section{Materials and methods}

Plant sample. The leaves of Acanthopanax henryi (Oliv.) Harms were collected in October 2012 in Xinhua (China). The plant species was confirmed by Professor Xiang-Qian Liu (Hunan Key Laboratory of Traditional Chinese Medicine modernization, Hunan University of Chinese Medicine, Changsha, China), and the voucher specimen (no. 20121125) was deposited at the School of Pharmacy, Hunan University of Chinese Medicine (Changsha, China).

Extraction and isolation. The dried leaves of A. henryi (Oliv.) Harms $(10 \mathrm{~kg})$ were cut into small pieces, were extracted three times with $\mathrm{MeOH}(3 \times 100 \mathrm{~L})$ at room temperature, and were concentrated to obtain a dark-green residue $(0.8 \mathrm{~kg})$ under reduced vacuum. The residue was then suspended in $\mathrm{H}_{2} \mathrm{O}$ and partitioned with petroleum ether. The water fraction

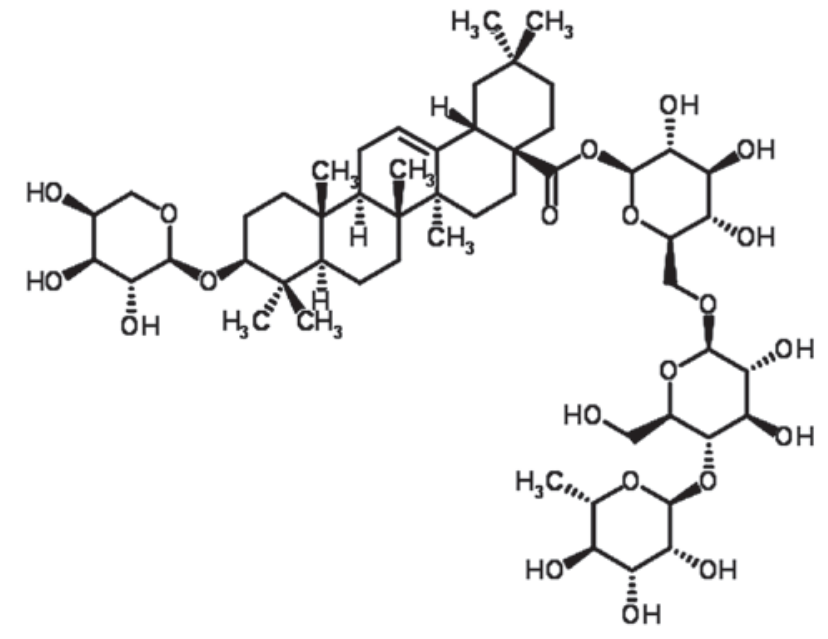

Figure 1. Structure of Ciwujianoside C3.

was fractionated using column chromatography (CC) on macroporous resin eluted with a gradient of EtOH/ $\mathrm{H}_{2} \mathrm{O}(0$, $30,50,75$ and $95 \%$ ) into five fractions (1-5). Fraction 4 (75\% $\mathrm{EtOH}, 14.0 \mathrm{~g}$ ) was subjected to silica gel $\mathrm{CC}$ eluted with $\mathrm{CHCl}_{3} / \mathrm{MeOH} / \mathrm{H}_{2} \mathrm{O}$ (25:1:0/1:1:0.2) to give fifteen fractions (A-O). Fraction $\mathrm{L}(0.67 \mathrm{~g})$ was refractionated on silica gel $\mathrm{CC}$ eluted with $\mathrm{CHCl}_{3} / \mathrm{MeOH} / \mathrm{H}_{2} \mathrm{O}$ (6:1:0.1/2:1:0.1) to give six sub-fractions (L1-L6). Sub-fraction L3 $(106.0 \mathrm{mg})$ was subjected to silica gel CC and was finally purified by Sephadex LH-20 (MeOH; GE Healthcare Life Sciences, Little Chalfont, UK) to yield $35.0 \mathrm{mg} \mathrm{CJS} \mathrm{C3} \mathrm{(24).}$

The compound structures were identified by mass spectroscopy, 1D-nuclear magnetic resonance (NMR) and 2D-NMR, and the spectral data were compared with those reported previously in the literature (24). ${ }^{1} \mathrm{H}$ NMR and ${ }^{13} \mathrm{C}$ NMR spectra were measured on a Varian INOVA 400M spectrometer (Agilent Technologies, Inc., Santa Clara, CA, USA) with chemical shifts reported as ppm (tetramethylsilane as internal standard). Electrospray ionization mass spectra were carried out on a Agilent 6530 Accurate-Mass Q-TOF (Agilent Technologies, Inc.).

High performance liquid chromatography (HPLC). The purity of CJS C3 was $>98 \%$, as determined HPLC, as previously described (25). Briefly, CJS C3 was dissolved in $\mathrm{MeOH}$ to a concentration of $0.1 \mathrm{mg} / \mathrm{ml}$, for HPLC analysis with Kinetex XB-C18 analytical column (100 mm x $4.6 \mathrm{~mm} \times 2.6 \mu \mathrm{m}$; Phenomenex, Inc., Torrance, CA, USA) at $30^{\circ} \mathrm{C}$. Elution was conducted using mobile phase A (water) and mobile phase $\mathrm{B}$ (acetonitrile) with a gradient as follows: 0-2 min, 29-31\% B; 2-13 min, 31-35\% B; 13-15 min, 35-40\% B; 15-23 min, $40-44 \% \mathrm{~B} ; 23-25 \mathrm{~min}, 44-46 \% \mathrm{~B} ; 25-31 \mathrm{~min}, 46-49 \% \mathrm{~B}$; $31-38 \mathrm{~min}, 49-55 \%$ B. The flow rate was constant at $1.0 \mathrm{ml} / \mathrm{min}$, and the effluents were monitored at $210 \mathrm{~nm}$ using an Agilent 1200 HPLC system with variable wavelength detector (Agilent Technologies, Inc.). The purity value was found to be $>98 \%$ by peak area normalization method. The value of purity was obtained by calculating the percentage of its peak area to that of the total peaks in the HPLC chromatogram.

Cell culture. The RAW 264.7 murine macrophage cell line was obtained from the Korea Research Institute of Bioscience 
Table I. Gene-specific primers used for PCR.

\begin{tabular}{|c|c|c|}
\hline PCR & Gene & Primer sequence \\
\hline \multirow[t]{5}{*}{ RT-PCR } & $\beta$-actin ${ }^{\mathrm{a}}$ & $\begin{array}{l}\text { Forward 5'-CATCCGTAAAGACCTCTATGCCAAC-3' } \\
\text { Reverse 5'-ATGGAGCCACCGATCCACA-3' }\end{array}$ \\
\hline & IL-6 & $\begin{array}{l}\text { Forward 5'-CATGTTCTCTGGGAAATCGTGG-3' } \\
\text { Reverse 5'-AACGCACTAGGTTTGCCGAGTA-3' }\end{array}$ \\
\hline & iNOS & $\begin{array}{l}\text { Forward 5'-AGCCCAACAATACAAATGACCCTA-3' } \\
\text { Reverse 5'-TTCCTGTTGTTTCTATTTCCTTTGT-3' }\end{array}$ \\
\hline & $\mathrm{COX}-2$ & $\begin{array}{l}\text { Forward 5'-CACTCAGTTTGTTGAGTCATTC-3' } \\
\text { Reverse 5'-GATTAGTACTGTAGGGTTAATG-3' }\end{array}$ \\
\hline & TNF- $\alpha$ & $\begin{array}{l}\text { Forward 5'-ACGGCATGGATCTCAAAGAC-3' } \\
\text { Reverse 5'-GTGGGTGAGGAGCAGTAGT-3' }\end{array}$ \\
\hline \multirow[t]{4}{*}{ RT-qPCR } & IL-6 & $\begin{array}{l}\text { Forward 5'-TCTATACCACTTCACAAGTCGGA-3' } \\
\text { Reverse 5'-GAATTGCCATTGCACAACTCTTT-3' }\end{array}$ \\
\hline & iNOS & $\begin{array}{l}\text { Forward 5'-GCAGAGATTGGAGGCCTTGTG-3' } \\
\text { Reverse 5'-GGGTTGTTGCTGAACTTCCAGTC-3' }\end{array}$ \\
\hline & COX-2 & $\begin{array}{l}\text { Forward 5'-GCCAGGCTGAACTTCGAAACA-3' } \\
\text { Reverse 5'-GCTCACGAGGCCACTGATACCTA-3' }\end{array}$ \\
\hline & TNF- $\alpha$ & $\begin{array}{l}\text { Forward 5'-ATGAGCACTGAAAGCATGATCC-3' } \\
\text { Reverse 5'-ATCCGTAAAGACCTCTATGCCAAC-3' }\end{array}$ \\
\hline
\end{tabular}

${ }^{a}$ The same $\beta$-actin primers were used for RT-PCR and RT-qPCR. RT, reverse transcription; q, quantitative; PCR, polymerase chain reaction; IL-6, interleukin-6; iNOS, inducible nitric oxide synthase; COX-2, cyclooxygenase.

and Biotechnology (Seoul, South Korea). The cells were cultured in RPMI 1640 medium (Gibco; Thermo Fisher Scientific, Inc., Waltham, MA, USA) supplemented with $10 \%$ fetal bovine serum (FBS; Dako UK Ltd., Cambridge, UK) and $100 \mathrm{U} / \mathrm{ml}$ penicillin/streptomycin sulfate. Cells were incubated in a humidified atmosphere containing $5 \% \mathrm{CO}_{2}$ at $37^{\circ} \mathrm{C}$. For stimulation, the medium was replaced with fresh RPMI 1640 , and the cells were stimulated with LPS $(200 \mathrm{ng} / \mathrm{ml}$; Sigma-Aldrich; Merck Millipore, Darmstadt, Germany) in the presence or absence of CJS C3 $(10,20$ and $40 \mu \mathrm{M})$.

Cell viability assay. Cell viability was determined using a 3-(4,5-dimethylthiazol-2-yl)-5-(3-carboxymethonyphenyl)-2 (4-sulfophenyl)-2H-tetrazolium (MTS) assay. RAW 264.7 cells were plated at a density of $5 \times 10^{4}$ cells $/ \mathrm{ml}$ in 96 -well plates (SPL Life Sciences Co., Ltd., Pocheon, Korea). Each experiment included a non-treated group as a control. To determine a concentration that was non-toxic to cells, various concentrations of CJS C3 $(10,20$ and $40 \mu \mathrm{M})$ were added to the cells and the plates were incubated for $24 \mathrm{~h}$ at $37^{\circ} \mathrm{C}$ in a $5 \% \mathrm{CO}_{2}$ atmosphere. MTS solution $(5 \mathrm{mg} / \mathrm{ml})$ was then added to each well and the cells were cultured for a further $2 \mathrm{~h}$, after which the optical density was measured at $490 \mathrm{~nm}$.

Measurement of $\mathrm{NO}$ production. NO production was assayed by measuring the nitrite concentration in the supernatant of cultured RAW 264.7 cells. Cells were seeded at a density of $7 \times 10^{5}$ cells $/ \mathrm{ml}$ in $96-w e l l$ culture plates and were cultured for $18 \mathrm{~h}$. The cells were stimulated with LPS $(200 \mathrm{ng} / \mathrm{ml})$ in the absence or presence of test reagents for $24 \mathrm{~h}$, after which they were briefly centrifuged. The supernatant was mixed with an equal volume of Griess reagent (1\% sulfanilamide,
$0.1 \%$ naphthyl ethylenediamine dihydrochloride and $2.5 \%$ $\mathrm{H}_{3} \mathrm{PO}_{4}$ ) and was incubated at room temperature for $5 \mathrm{~min}$. Nitrite concentrations were determined by measuring the absorbance of the supernatant at $570 \mathrm{~nm}$. Sodium nitrite $\left(\mathrm{NaNO}_{2}\right)$ was used to generate a standard curve.

Enzyme-linked immunosorbent assay (ELISA). Cells were seeded at a density of $5 \times 10^{5}$ cells $/ \mathrm{ml}$ in 24 -well tissue culture plates and were treated with CJS C3 $(10,20$, and $40 \mu \mathrm{M})$ for $1 \mathrm{~h}$, prior to stimulation with LPS (200 ng/ml). Following an incubation at $37^{\circ} \mathrm{C}$ for $24 \mathrm{~h}$, the medium was collected in a microcentrifuge tube and centrifuged $(2,000 \times \mathrm{g}, 5 \mathrm{~min}$, $4^{\circ} \mathrm{C}$ ). Levels of TNF- $\alpha$ and IL- 6 in the culture media were quantified using ELISA kits (cat. nos. 555240 and 555268, respectively), according to the manufacturer's protocol (BD Biosciences, San Jose, CA, USA). ELISA plates (Falcon; BD Biosciences) were coated overnight at $4^{\circ} \mathrm{C}$ with anti-mouse interleukin (IL)-6 antibody (1:1,000; cat. no. 554402) and TNF- $\alpha$ antibody (1:250; cat. no. 51-26731E) diluted in coating buffer (0.1 M sodium carbonate; $\mathrm{pH} 9.5)$ and were washed three times with phosphate-buffered saline (PBS) containing $0.05 \%$ Tween-20. Non-specific protein binding sites were subsequently blocked with assay diluent (PBS containing $10 \% \mathrm{FBS} ; \mathrm{pH} 7.0$ ) for $\geq 1 \mathrm{~h}$. Immediately following this incubation, samples and IL-6 standards were added to the wells, and the plates were incubated for a further $2 \mathrm{~h}$. Subsequently, detector solution [biotinylated anti-mouse IL-6 monoclonal antibody (1:1,000; cat. no. 554402), TNF- $\alpha$ monoclonal antibody (1:500; cat. no. 51-26732E) and streptavidin-horseradish peroxidase (HRP) reagent $(1: 1,000$; cat. no. 554066) all from BD Biosciences] was added to each well and the plates were incubated for an additional 
$1 \mathrm{~h}$. Tetramethylbenzidine was added to each well, and the plates were incubated for $30 \mathrm{~min}$ in the dark prior to reaction termination using stop solution $\left(1 \mathrm{M} \mathrm{H}_{3} \mathrm{PO}_{4}\right)$. Absorbance was then measured at $450 \mathrm{~nm}$. All standards and samples were assayed in duplicate.

Measurement of $\mathrm{PGE}_{2}$ production. $\mathrm{PGE}_{2}$ concentrations were determined using a $\mathrm{PGE}_{2}$ direct Biotrak assay (cat. no. Amersham; GE Healthcare Life Sciences). Cells were seeded at a density of $5 \times 10^{5}$ cells $/ \mathrm{ml}$ in 24-well tissue culture plates. CJS C3 (10, 20 and $40 \mu \mathrm{M})$ and LPS (200 ng/ml) were added to the culture medium and the plates were incubated at $37^{\circ} \mathrm{C}$ for $24 \mathrm{~h}$. The medium was then collected in microcentrifuge tubes and centrifuged $\left(2,000 \times \mathrm{g}, 5 \mathrm{~min}, 4^{\circ} \mathrm{C}\right)$. The supernatants were decanted into fresh microcentrifuge tubes and the concentration of $\mathrm{PGE}_{2}$ was determined using the enzyme immunoassay kit, according to the manufacturer's protocol.

Western blot analysis. CJS C3-pretreated (10, 20 and $40 \mu \mathrm{M})$ RAW 264.7 cells $\left(2 \times 10^{6}\right.$ cells $\left./ \mathrm{ml}\right)$ were stimulated with LPS (200 $\mathrm{ng} / \mathrm{ml})$ for $24 \mathrm{~h}$ and were then washed twice in ice-cold PBS (pH 7.4). The cell pellets were resuspended in lysis buffer on ice for $20 \mathrm{~min}$ and cell debris was removed by centrifugation $\left(2,000 \times \mathrm{g}, 5 \mathrm{~min}, 4^{\circ} \mathrm{C}\right)$. The protein concentration in each sample was determined using the Bio-Rad protein assay reagent (Bio-Rad Laboratories, Inc., Hercules, CA, USA) according to the manufacturer's protocol. Equal amounts of protein $(20 \mu \mathrm{g})$ were separated by $8 \%$ sodium dodecyl sulfate-polyacrylamide gel electrophoresis and were then transferred onto a polyvinylidene fluoride membrane (EMD Millipore, Bedford, MA, USA). The membrane was blocked with 5\% non-fat milk in Tris-buffered saline with Tween 20 (150 mmol/1 NaCl, $20 \mathrm{mmol} / \mathrm{l}$ Tris- $\mathrm{HCl}$ and $0.05 \%$ Tween 20 ; $\mathrm{pH}$ 7.4). After blocking with $3 \%$ bovine serum albumin (Sigma-Aldrich; Merck Millipore), the membranes were incubated with the following primary antibodies: Anti-iNOS (1:1,000; cat. no. sc-651), anti-COX-2 (1:1,000; cat. no. sc-1745), anti-mouse-phosphorylated-ERK 1/2 MAPK (1:1,000; cat. no. sc-7383), anti-phosphorylated-JNK (1:1,000; cat. no. sc-6254), anti-ERK (1:1,000; cat. no. sc-93) and JNK (1:1,000; cat. no. sc-571) all obtained from Santa Cruz Biotechnology, Inc. (Dallas, TX, USA) for $18 \mathrm{~h}$ at $4^{\circ} \mathrm{C}$. After washing twice with Tris-buffered saline, membranes were immunoblotted with HRP-conjugated anti-immunoglobulin G antibody (1:2,000; cat. no. Z025902; Dako UK Ltd.) for $1 \mathrm{~h}$ at room temperature. Epitopes on proteins were recognized specifically by the antibodies and were visualized using an enhanced chemiluminescence kit (Amersham; GE Healthcare Life Sciences). The membrane was also immunoblotted with anti- $\beta$-actin (1:1,000; cat. no. 47778; Santa Cruz Biotechnology, Inc.) to demonstrate equal protein loading. The bands were evaluated by using ImageQuant LAS 4000 Mini Biomolecular Imager (GE Healthcare) and the quantitative measurement of band intensity was performed using ImageJ (version 1.45S; National Institutes of Health, Bethesda, MA, USA)

RNA isolation and cDNA synthesis. Using the Easy Blue total RNA Extraction kit (iNtRon Biotechnology, Seongnam, South Korea) total RNA was extracted from RAW 264.7 cells, according to the manufacturer's protocol. Total RNA was then dissolved in DEPC-treated distilled water. RNA samples used in the present study had an A260/A280 nm value between 1.6 and 2.0, as determined using a NanoDrop spectrophotometer (Thermo Fisher Scientific, Inc., Pittsburgh, PA, USA). A Power cDNA synthesis kit (iNtRon Biotechnology) was used to reverse transcribe each sample to cDNA. Reverse transcription (RT) conditions were as follows: $5 \mathrm{~min}$ at $75^{\circ} \mathrm{C}, 1 \mathrm{~h}$ at $42^{\circ} \mathrm{C}$ and $5 \mathrm{~min}$ at $70^{\circ} \mathrm{C}$.

$R T$-polymerase chain reaction $(P C R)$ analysis. Synthesized cDNA $(0.05 \mu \mathrm{g})$ from RAW 264.7 cells was amplified using Sensi 2X PCR premix (Lugen Sci Co., Ltd., Bucheon, Korea) and specific primers (Table I). The conditions for amplification were as follows: Denaturation at $94^{\circ} \mathrm{C}$ for $3 \mathrm{~min}$ for one cycle, followed by 35 cycles of denaturation at $94^{\circ} \mathrm{C}$ for $45 \mathrm{sec}$, annealing at $56^{\circ} \mathrm{C}$ for $45 \mathrm{sec}$ (iNOS), $53^{\circ} \mathrm{C}$ for $45 \mathrm{sec}(\mathrm{COX}-2)$ or $57^{\circ} \mathrm{C}$ for $45 \mathrm{sec}$ (IL-6), and extension at $72^{\circ} \mathrm{C}$ for $90 \mathrm{sec}$. A final extension step was performed at $72^{\circ} \mathrm{C}$ for $7 \mathrm{~min}$. The PCR products were separated by $2 \%$ agarose gel electrophoresis and were stained with Dyne Gel Safe Red kit (II) (Dyne Bio, Seongnam, South Korea). The expression levels were confirmed using a UV detector.

RT-quantitative (q)PCR analysis. Synthesized cDNA from RAW 264.7 cells was amplified using specific primers (Table I) and the Fast SYBR Green PCR Master Mix (Applied Biosystems; Thermo Fisher Scientific, Inc., Waltham, MA, USA). PCR products were measured using a StepOnePlus Real-Time RT-PCR system (Thermo Fisher Scientific, Inc.). Relative gene expression was calculated based on the comparative quantification cycle $(\mathrm{Cq})$ method (26), using StepOne software v2.3 (Applied Biosystems; Thermo Fisher Scientific, Inc.). $\beta$-actin mRNA expression was used as an endogenous control.

Immunofluorescence staining. RAW 264.7 cells were cultured in Nunc ${ }^{\mathrm{TM}}$ chambered coverglass (Thermo Fisher Scientific, Inc.) for $24 \mathrm{~h}$ and were stimulated with LPS in the presence or absence of CJS C3 (10, 20 and $40 \mu \mathrm{M})$. The cells were fixed in $4 \%$ formaldehyde in PBS for $15 \mathrm{~min}$ at room temperature, and were permeabilized with $100 \% \mathrm{MeOH}$ for $10 \mathrm{~min}$ at $-20^{\circ} \mathrm{C}$. Specimens were blocked with blocking buffer (PBS containing 5\% FBS and $0.3 \%$ Triton X-100) for $1 \mathrm{~h}$, and were incubated overnight with anti-NF- $\kappa \mathrm{B} / \mathrm{p} 65$ antibody (1:200; cat. no. sc-8008; Santa Cruz Biotechnology, Inc.) at $4^{\circ} \mathrm{C}$. Fluorochrome-conjugated secondary antibodies (1:500; cat. no. A11029; Thermo Fisher Scientific, Inc.) were then applied for $1 \mathrm{~h}$ at room temperature in the dark. After washing with PBS, nuclei were counterstained with 4', 6-diamidino-2-phenylindole, and fluorescence was visualized under a fluorescence microscope (Carl Ziess, Oberkochen, Germany).

Cells were stimulated with Alexa Fluor (AF)-LPS (Sigma-Aldrich; Merck Millipore) for $1 \mathrm{~h}$ in the presence or absence of CJS C3 for the LPS/TLR4 complex formation assay. The cells were fixed and stained with a rabbit polyclonal anti-TLR4 antibody (1:200; sc-16240; Santa Cruz Biotechnology, Inc.) overnight at $4^{\circ} \mathrm{C}$. Subsequently, the cells were incubated with AF 488-conjugated secondary antibodies (1:500; cat. no. A11029; Thermo Fisher Scientific, Inc.) for $1 \mathrm{~h}$. 


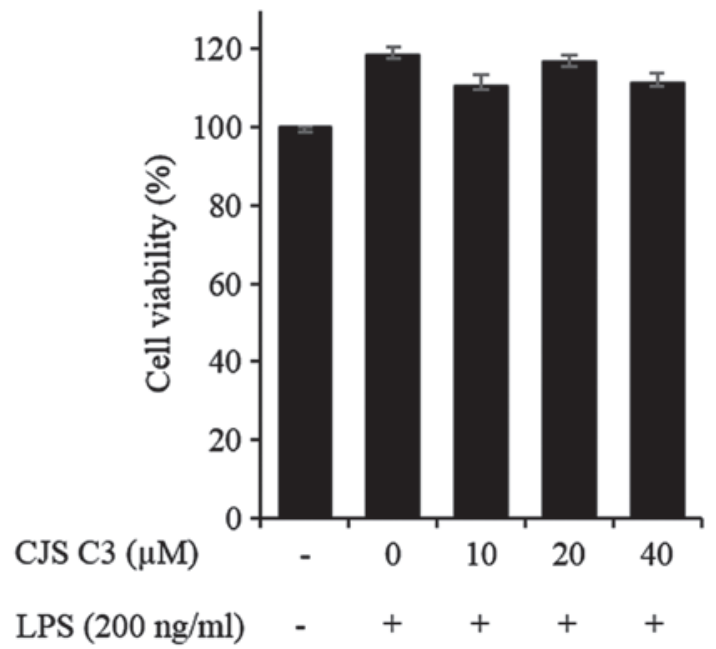

Figure 2. Effects of Ciwujianoside C3 (CJS C3) on viability of RAW 264.7 cells. RAW 264.7 cells were pretreated with the indicated concentrations of CJS C3 for $1 \mathrm{~h}$ prior to being incubated with lipopolysaccharide (LPS; $200 \mathrm{ng} / \mathrm{ml}$ ) for $24 \mathrm{~h}$. Cell viability was assessed using an MTS assay. The experiment was repeated three times, and similar results were obtained. Data are presented as the mean \pm standard deviation of duplicate determinations from three separate experiments.

The stained cells were observed under a fluorescence microscope.

Statistical analysis. Statistical analysis was performed using one-way analysis of variance followed by Tukey honest significant difference test for multiple comparisons. Data are presented as the mean \pm standard deviation of duplicate determinations from three separate experiments. SPSS 22 software (IBM SPSS, Armonk, NY, USA) was used to conduct statistical analysis. $\mathrm{P}<0.05$ was considered to indicate a statistically significant difference.

\section{Results}

Effects of CJS C3 on cytotoxicity and NO production in RAW 264.7 cells. CJS C3 did not affect the viability of RAW 264.7 cells when used at the following concentrations: 10, 20 and $40 \mu \mathrm{M}$ (Fig. 2). NO production was examined in LPS-stimulated RAW 264.7 cells in the presence or absence of CJS C3 for $24 \mathrm{~h}$ by Griess assay. Supernatants from LPS-stimulated cells had significantly increased nitrite levels compared with the controls. The effects of LPS were inhibited following treatment with 20 or $40 \mu \mathrm{M}$ CJS C3(Fig. 3).

Effects of CJS C3 on PGE $E_{2}$ production in LPS-stimulated $R A W 264.7$ cells. The effects of CJS C3 on LPS-induced secretion of $\mathrm{PGE}_{2}$ were examined by ELISA. As presented in Fig. 4, treatment of RAW 264.7 cells with LPS resulted in a marked increase in $\mathrm{PGE}_{2}$ release compared with in the untreated control group. However, CJS C3 inhibited LPS-mediated $\mathrm{PGE}_{2}$ production in a concentration-dependent manner.

Effects of CJS C3 on IL-6 and tumor necrosis factor (TNF)- $\alpha$ production in LPS-stimulated RAW 264.7 cells. The effects of CJS C3 on secretion of inflammatory cytokines, such as IL-6 and TNF- $\alpha$, were evaluated in LPS-treated RAW 264.7

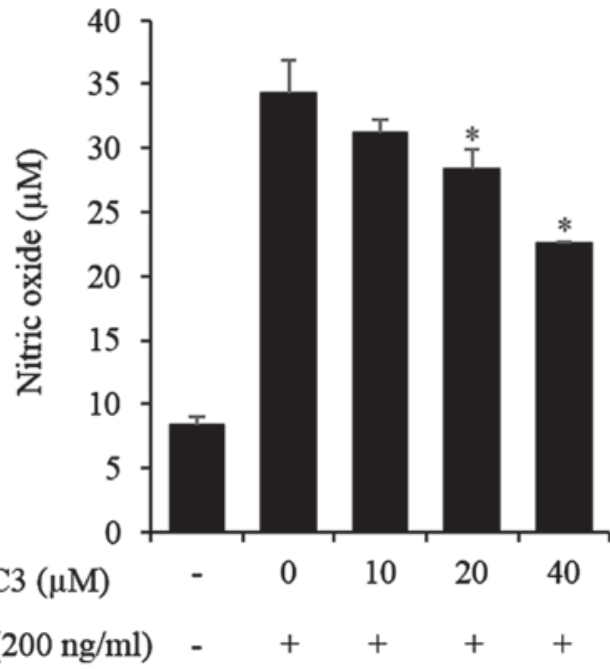

Figure 3. Effects of Ciwujianoside C3 (CJS C3) on lipopolysaccharide (LPS)-induced nitric oxide (NO) production in RAW 264.7 cells. RAW 264.7 cells were pretreated with the indicated concentrations of CJS C3 for $1 \mathrm{~h}$ prior to being incubated with LPS (200 ng/ml) for $24 \mathrm{~h}$. NO production was measured using the Griess reaction. Data are presented as the mean \pm standard deviation of duplicate determinations from three separate experiments. ${ }^{*} \mathrm{P}<0.05$ compared with the LPS-treated group.

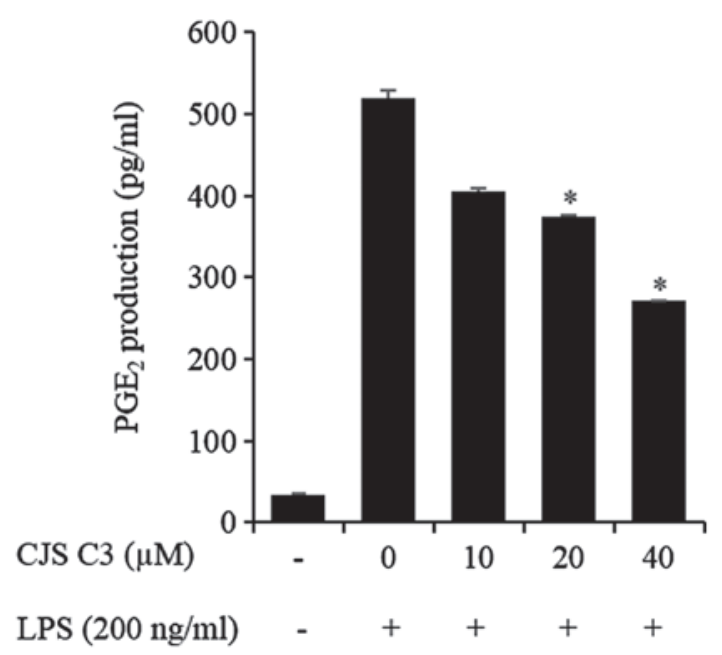

Figure 4. Effects of Ciwujianoside C3 (CJS C3) on lipopolysaccharide (LPS)-induced prostaglandin $\mathrm{E}_{2}\left(\mathrm{PGE}_{2}\right)$ production in RAW 264.7 cells. RAW 264.7 cells were pretreated with the indicated concentrations of CJS C3 for $1 \mathrm{~h}$ prior to being incubated with LPS (200 $\mathrm{ng} / \mathrm{ml})$ for $24 \mathrm{~h}$. $\mathrm{PGE}_{2}$ production was measured in the culture medium using a commercial enzyme-linked immunosorbent assay kit. Data are presented as the mean \pm standard deviation of duplicate determinations from three separate experiments. ${ }^{*} \mathrm{P}<0.05$, compared with the LPS-treated group.

cells. IL-6 and TNF- $\alpha$ levels were significantly increased in the culture medium of LPS-stimulated RAW 264.7 cells. However, pretreatment with CJS C3 significantly decreased the release of these cytokines in a concentration-dependent manner (Fig. 5A and B). Furthermore, the results of an RT-PCR indicated that CJS C3 also markedly suppressed the mRNA expression levels of these cytokines (Fig. 5C and D).

Effects of CJS C3 on LPS-stimulated COX-2 and iNOS expression in RAW 264.7 cells. To elucidate the mechanism underlying decreased $\mathrm{PGE}_{2}$ levels and $\mathrm{NO}$ production in 

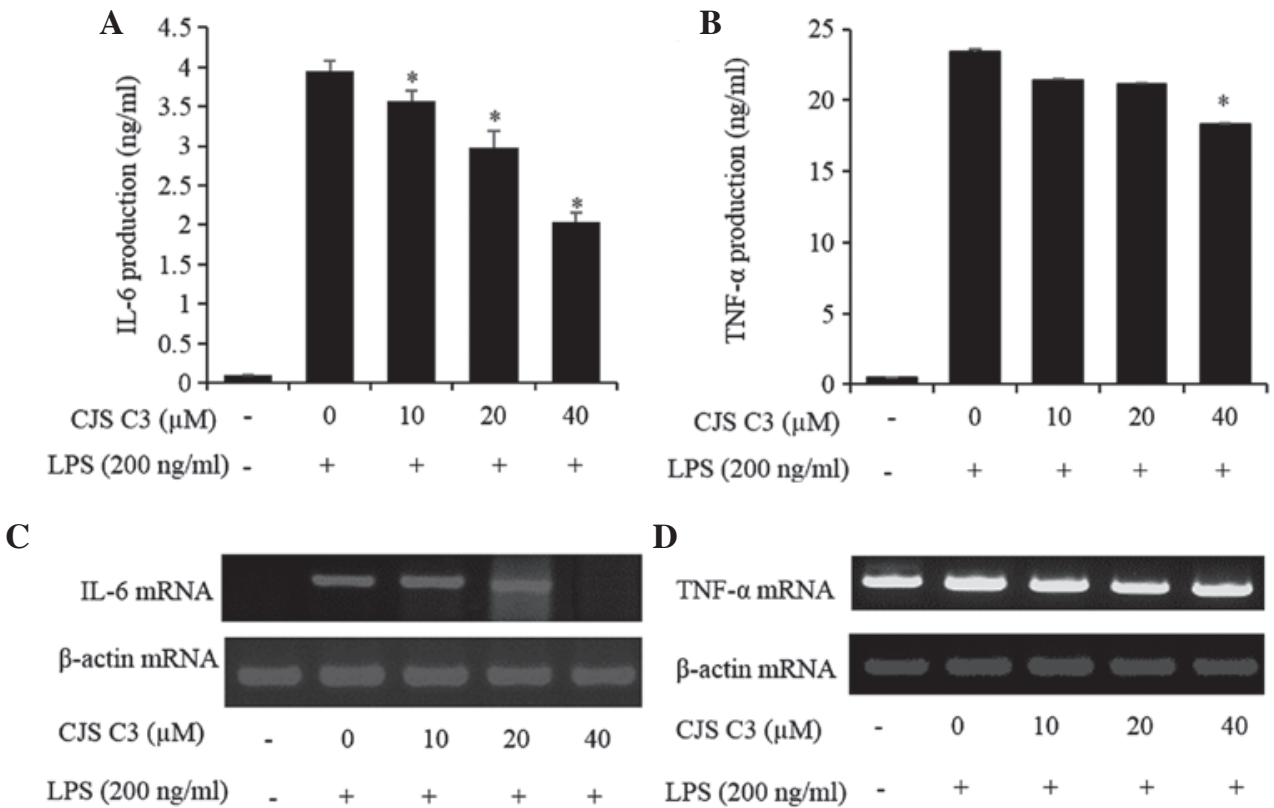

D

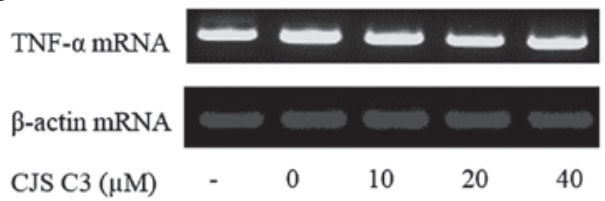

Figure 5. Effects of Ciwujianoside C3 (CJS C3) on lipopolysaccharide (LPS)-induced interleukin (IL)- 6 and tumor necrosis factor (TNF)- $\alpha$ production in RAW 264.7 cells. RAW 264.7 cells were pretreated with the indicated concentrations of CJS C3 for $1 \mathrm{~h}$ prior to being incubated with LPS (200 ng/ml) for $24 \mathrm{~h}$. (A) IL-6 and (B) TNF- $\alpha$ production were measured in the culture medium using enzyme-linked immunosorbent assay kits. mRNA expression levels of (C) IL-6 and (D) TNF- $\alpha$ were visualized by reverse transcription-polymerase chain reaction. Data are presented as the mean \pm standard deviation of duplicate determinations from three separate experiments. ${ }^{*} \mathrm{P}<0.05$ compared with the LPS-treated group.
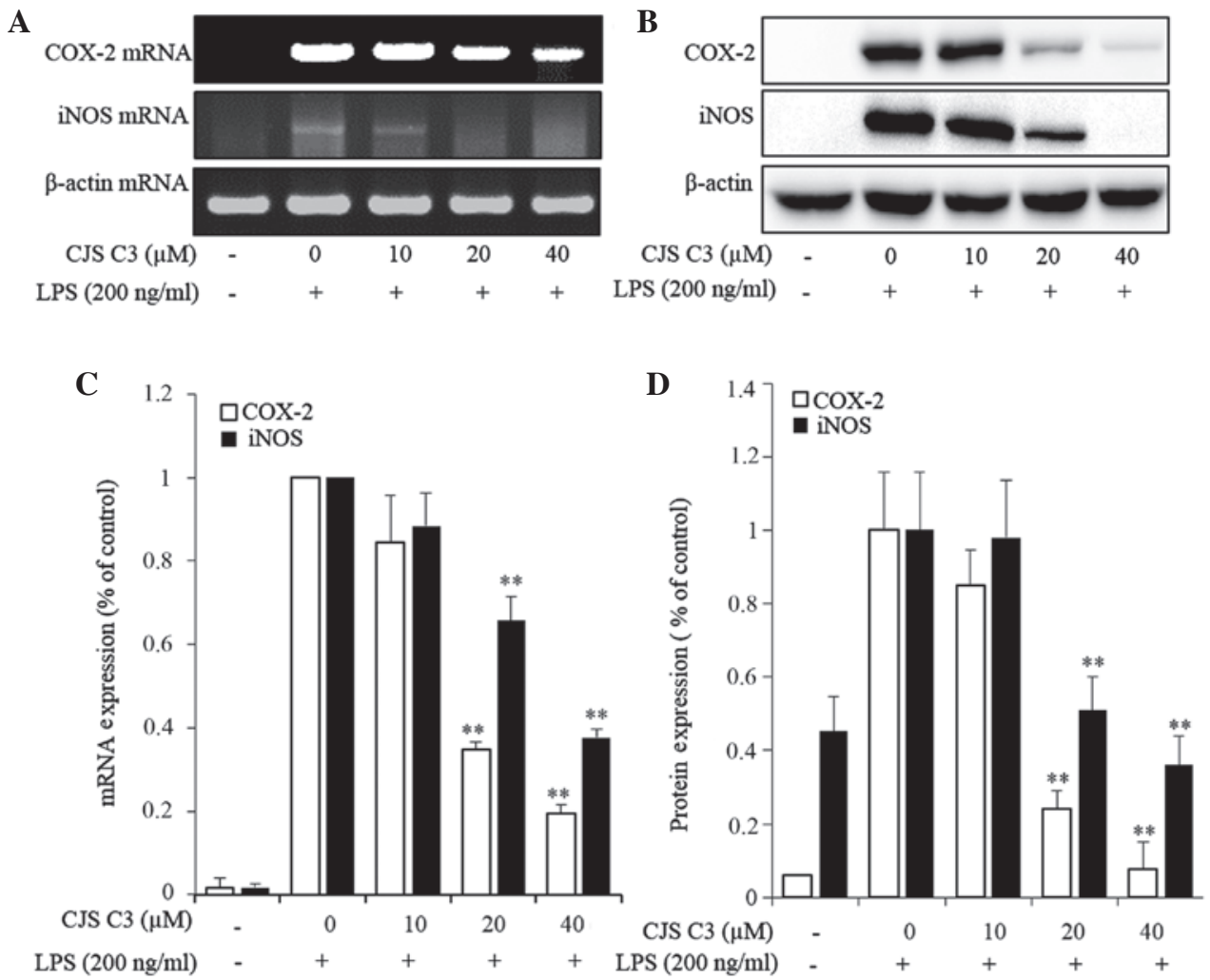

Figure 6. Inhibition of inducible nitric oxide synthase (iNOS) and cyclooxygenase (COX)-2 expression by Ciwujianoside C3 (CJS C3) in lipopolysaccharide (LPS)-stimulated RAW 264.7 cells. (A) iNOS and COX-2 mRNA expression was visualized by reverse transcription (RT)-polymerase chain reaction (PCR), and (B) protein levels were detected by western blotting. (C) RT-quantitative PCR was conducted to quantify mRNA expression levels, and (D) western blotting was semi-quantified against $\beta$-actin using ImageJ software. Data are presented as the mean \pm standard deviation of duplicate determinations from three separate experiments. ${ }^{* *} \mathrm{P}<0.01$ compared with the LPS-treated group. 
undetectable in unstimulated murine macrophages. However, the mRNA and protein expression levels of COX-2 and iNOS were markedly increased in response to LPS stimulation. In the CJS C3 treatment group IL-6 and COX-2 expression exhibited a significant concentration-dependent inhibition (Fig. 6). These results indicate that decreased COX-2 and iNOS expression may contribute to the inhibitory effects of CJS C3 on LPS-stimulated $\mathrm{NO}$ and $\mathrm{PGE}_{2}$ production.

Effects of CJS C3 on the phosphorylation of MAPKs in LPS-stimulated RAW 264.7 cells. Since MAPK signaling molecules have a crucial role in regulating the LPS-induced inflammatory process, the present study analyzed the phosphorylation levels of MAPKs in LPS-stimulated RAW 264.7 cells by western blotting. In addition, the effects of CJS C3 on phosphorylation of ERK and JNK MAPKs were determined in LPS-treated cells. As presented in Fig. 7, ERK and JNK phosphorylation was effectively suppressed by CJS C3 treatment. These results suggest that activation of ERK and JNK may be blocked by CJS C3 treatment.

Effects of CJS C3 on LPS-induced nuclear translocation of $N F-\kappa B$ in $R A W 264.7$ macrophages. NF- $\kappa \mathrm{B}$ is an important transcription factor that regulates the expression of iNOS, COX-2 and proinflammatory cytokines. Therefore, using immunofluorescence staining, the present study investigated whether CJS C 3 could suppress the $\mathrm{NF}-\kappa \mathrm{B}$ signaling pathway. The immunofluorescence images revealed that $\mathrm{NF}-\kappa \mathrm{B} / \mathrm{p} 65$ was normally sequestered in the cytoplasm, and that nuclear accumulation of NF- $\mathrm{NB} / \mathrm{p} 65$ was strongly induced following stimulation of RAW 264.7 cells with LPS. LPS-induced translocation of $\mathrm{NF}-\kappa \mathrm{B} / \mathrm{p} 65$ was completely inhibited after pretreating the cells with CJS C3 (Fig. 8, Merge panel).

Effects of CJS C3 on LPS binding and TLR4 expression. The present study also investigated the effects of CJS C3 on the LPS-activated TLR4 signaling pathway, in order to further determine the mechanisms underlying its anti-inflammatory effects. AF-LPS was used to determine whether CJS C3 was able to inhibit the interaction between LPS and TLR4 in murine macrophages. When the cells were treated with AF-LPS alone, the fluorescence intensities of LPS and TLR4 were observed outside the cell membrane by immunofluorescence assay. However, treatment with AF-LPS and CJS C3 significantly inhibited the fluorescence intensity of TLR4 (Fig. 9A and B). These results suggest that LPS-stimulated activation of the TLR4 signaling pathway was potently suppressed by CJS C3.

\section{Discussion}

The Acanthopanax spp. belongs to the Araliaceae family, the stem barks and roots of which have been used as a tonic and as a prophylactic treatment in Oriental medicine according to ancient use (26). Acanthopanax henryi Harms is a member of the Acanthopanax spp., the stem bark of which was originally used to treat arthritis, rheumatism, edema and traumatic injuries in China (27). Recently, Acanthopanax henryi Harms leaves have started to garner the attention of researchers. The present study demonstrated that CJS C3, extracted from the leaves of Acanthopanax henryi Harms, indicated anti-inflammatory

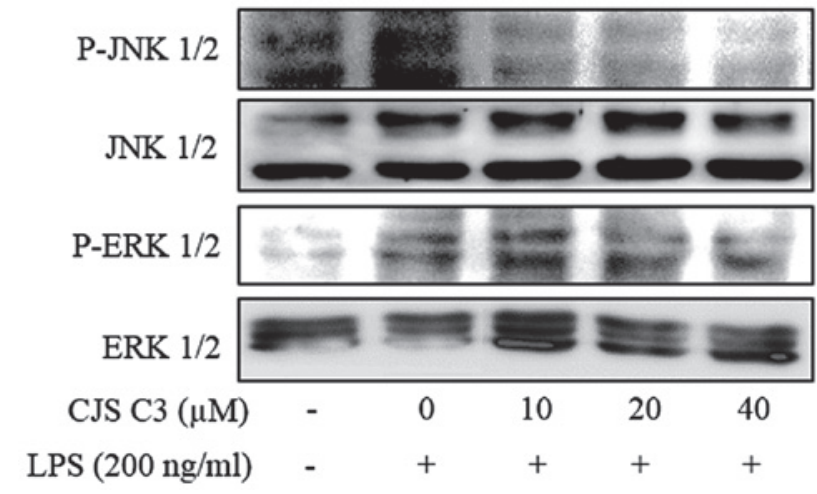

Figure 7. Effects of Ciwujianoside C3 (CJS C3) on the phosphorylation of mitogen-activated protein kinases in lipopolysaccharide (LPS)-stimulated RAW 264.7 cells, as determined by western blot analysis. RAW 264.7 cells were pretreated with the indicated concentrations of CJS C3 for $1 \mathrm{~h}$ prior to being incubated with LPS $(200 \mathrm{ng} / \mathrm{ml})$ for $1 \mathrm{~h}$. The experiment was repeated three times, and similar results were obtained. P-, phosphorylated; JNK, c-jun N-terminal kinases; ERK, extracellular signal-regulated kinases.

activity in LPS-stimulated RAW 264.7 cells The reported pharmacological effects of active components extracted from the leaves of Acanthopanax henryi Harms include inhibition of tryrosinase and acetylcholinesterase $(6,28)$. To the best of our knowledge, no other studies have been conducted regarding Acanthopanax henryi Harms leaves. CJS C3, which was extracted from Acanthopanax henryi Harms leaves in the present study, has also been isolated from Acanthopanax senticosus (29). The present study aimed to determine the anti-inflammatory effects of CJS C3, extracted from Acanthopanax henryi Harms leaves, on LPS-stimulated RAW 264.7 cells.

Inflammation implies an irregularity in cytokine levels. Proinflammatory cytokines, such as IL-6 and TNF- $\alpha$, have important roles in several inflammatory processes, and recruit other immune cells involved in the pathogenesis of various inflammatory conditions. Accordingly, overproduction of IL-6 and TNF- $\alpha$ is associated with the development of chronic inflammatory conditions, including septic shock, cachexia, psoriasis, rheumatoid arthritis and cytotoxicity (30-33). Therefore, the present study investigated the effects of CJS C 3 on the synthesis of proinflammatory cytokines. The results demonstrated that CJS C3 effectively suppressed the overproduction of IL- 6 and TNF- $\alpha$ in a concentration-dependent manner (Fig. 5A and B). The suppressing effect extended to the inhibition of TNF- $\alpha$ and IL-6 transcription (Fig. 5C and D).

Production of IL- 6 and TNF- $\alpha$ is associated with synergistic activation of $\mathrm{NO}$ and $\mathrm{PGE}_{2}$ production in LPS-activated RAW 264.7 macrophages (32-34). NO is generated by phagocytes, such as monocytes, macrophages and neutrophils. Phagocytes contain iNOS, which is activated by interferon- $\gamma$ or TNF. In this manner, the immune system regulates phagocytes, which have a key role in inflammation and immune responses (35-39).

Among the PGs, $\mathrm{PGE}_{2}$ is the most prominent mediator in inflammation, fever and pain; it also has physiological functions in the gastrointestinal tract, kidney, and the immune and central nervous systems. Increased $\mathrm{PGE}_{2}$ formation during inflammation predominantly depends on the concomitant induction of COX-2 (40). 


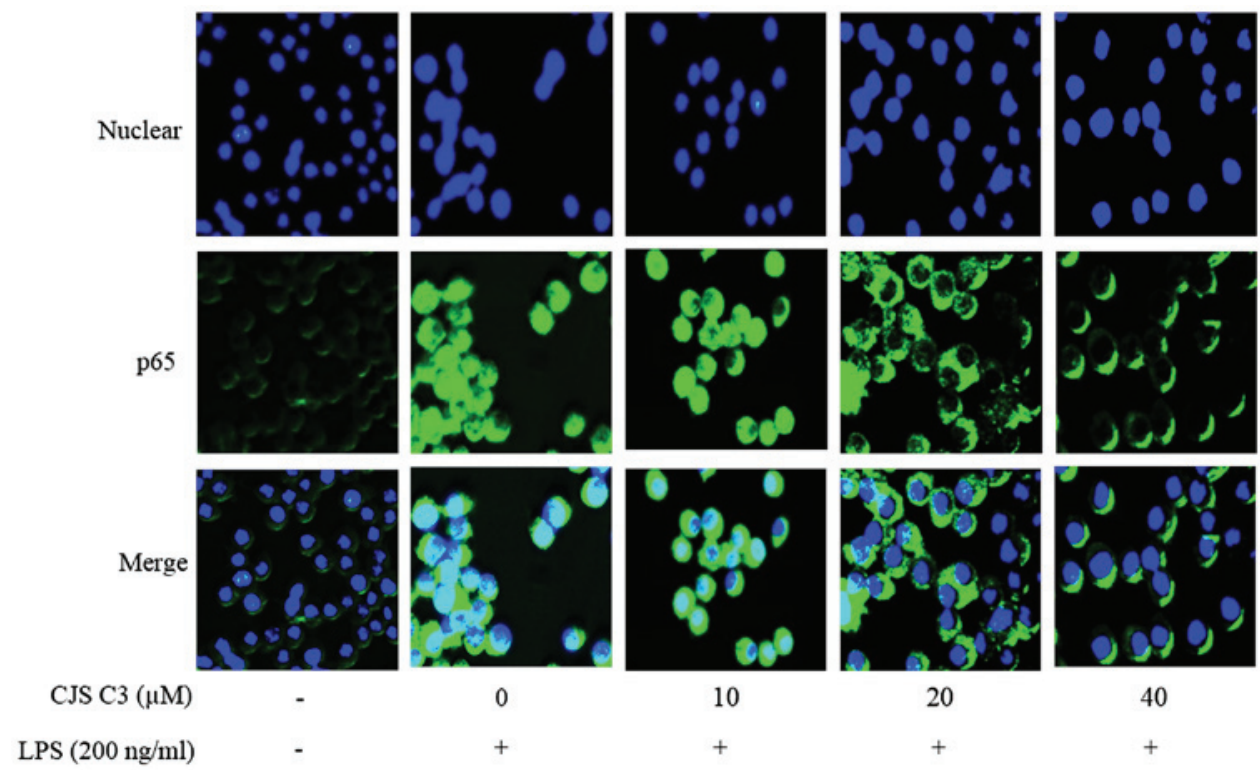

Figure 8. Effects of Ciwujianoside C3 (CJS C3) on lipopolysaccharide (LPS)-induced nuclear translocation of nuclear factor (NF)-kB in RAW 264.7 macrophages. Cells were pretreated with 10,20 or $40 \mu \mathrm{M}$ CJS C 3 for $1 \mathrm{~h}$ prior to stimulation with LPS for $1 \mathrm{~h}$. Localization of NF-kB/p65 was visualized with a fluorescence microscope after immunofluorescence staining with anti-NF- $\mathrm{\kappa B} / \mathrm{p} 65$ and fluorescein isothiocyanate-labeled anti-rabbit immunoglobulin $\mathrm{G}$ antibodies (green). Nuclei of the corresponding cells were visualized with 4,6-diamidino-2-phenylindole (blue). The experiment was repeated three times, and similar results were obtained. x200 magnification.

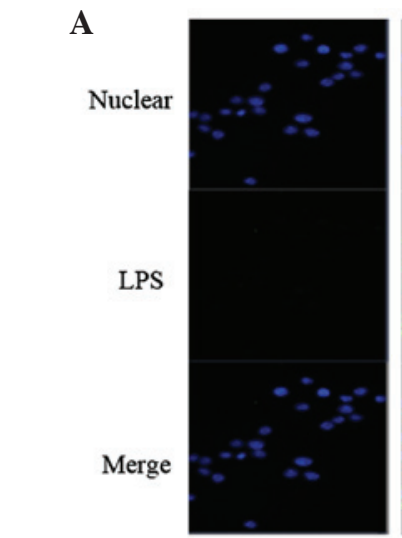

$\operatorname{CJS} \mathrm{C} 3(\mu \mathrm{M})$

LPS $(200 \mathrm{ng} / \mathrm{ml})$

B

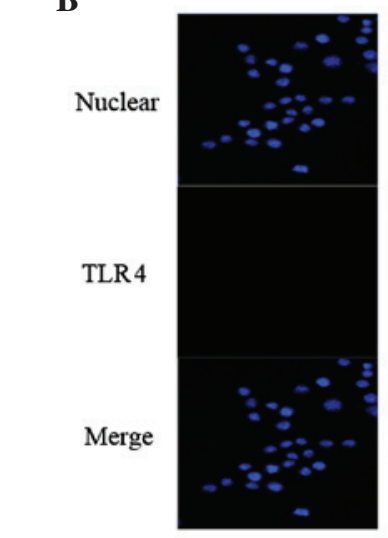

CJS C3 $(\mu \mathrm{M})$

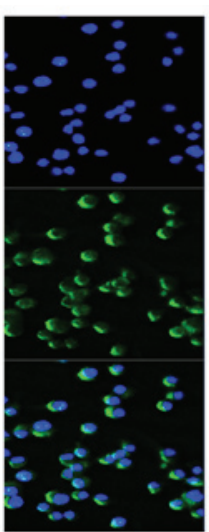

0

$+$

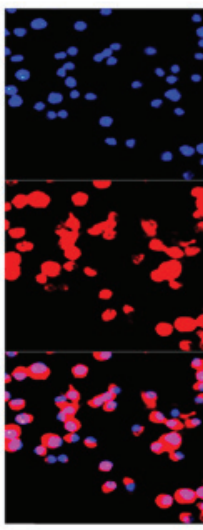

0

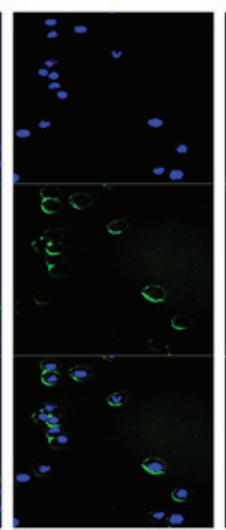

10

$+$

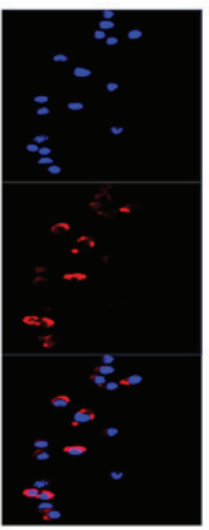

10

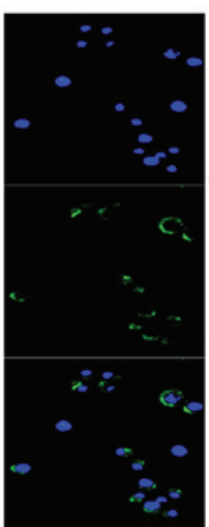

20

$+$

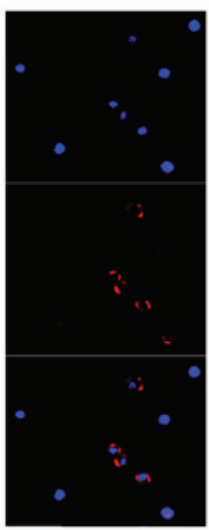

20

$+$

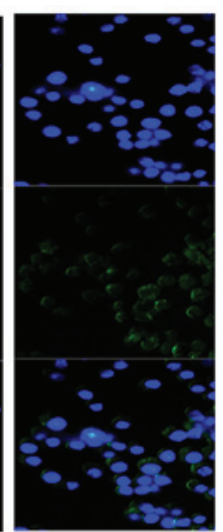

40

$+$

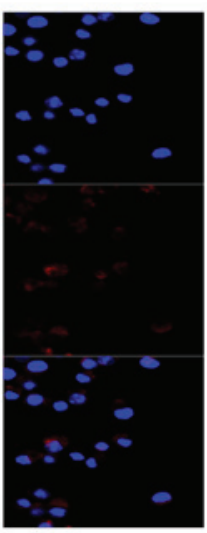

40

LPS $(200 \mathrm{ng} / \mathrm{ml})$

Figure 9. Effects of Ciwujianoside C3 (CJS C3) on the binding of lipopolysaccharide (LPS) and expression of Toll-like receptor (TLR) 4. (A) Cells were pretreated with 10,20 or $40 \mu \mathrm{M}$ CJS C3 for $1 \mathrm{~h}$ prior to stimulation with $200 \mathrm{ng} / \mathrm{ml}$ Alexa Fluor (AF)-LPS for $30 \mathrm{~min}$. (B) TLR4 was then detected by fluorescence microscopy using a rabbit polyclonal anti-TLR4 antibody. Nuclei of the corresponding cells were visualized with 4,6-diamidino-2-phenylindole (blue). The experiment was repeated three times, and similar results were obtained. x200 magnification. 
According to the results of the present study, CJS C3 significantly inhibited LPS-induced $\mathrm{NO}$ and $\mathrm{PGE}_{2}$ production in RAW 264.7 cells (Figs. 3 and 4). This suppression was possibly caused by inhibition of iNOS and COX-2 expression at the transcriptional level in LPS-stimulated RAW 264.7 cells (Fig. 6).

MAPKs are involved in directing cellular responses to a diverse array of stimuli, including mitogens, osmotic stress, heat shock and proinflammatory cytokines. They regulate cell functions, including proliferation, gene expression, differentiation, mitosis, cell survival and apoptosis (41). The MAPK family consists of serine/threonine kinases, such as ERK, p38 MAPK and JNK (42), which control cellular signal transduction from the cell surface to the nucleus. Furthermore, phosphorylation and activation of MAPKs has previously been implicated in signaling pathways relevant to LPS-induced inflammation, thus suggesting that MAPKs are important targets for anti-inflammatory molecules $(43,44)$.

$\mathrm{NF}-\mathrm{kB}$ is a protein complex that controls transcription of DNA $(19,20)$. NF- $\kappa B$ regulates the expression of several genes that code for mediators involved in immune and inflammatory responses, including iNOS, COX-2, TNF- $\alpha$ and IL-6. Therefore, NF- $\mathrm{KB}$ is considered a rational target for novel types of anti-inflammatory treatment $(45,46)$. The present data indicated that the effects of CJS C3 appear to involve inhibition of NF- $\mathrm{KB}$ activation by blocking the MAPK signaling pathway (Fig. 7 and 8).

LPS-activated macrophages, which bind to TLR4, induce the activation of specific intracellular pathways through receptor dimerization and recruitment of various adapter molecules, such as myeloid differentiation primary response 88 (47). These LPS-initiated signaling cascades lead to activation of the MAPK and NF- $\kappa B$ signaling pathways (48). The results of the present study demonstrated that treatment of LPS-stimulated macrophages with CJS C 3 significantly inhibited the fluorescence intensity of TLR4 (Fig. 9). The results of the present study suggest that the anti-inflammatory properties of CJS C3 may result from inhibition of pro-inflammatory mediators by suppressing the initiation of the inflammatory response and inhibiting the MAPK-NF- $\kappa$ B signaling pathways.

\section{Acknowledgements}

The present study was supported by the Basic Science Research Program through the National Research Foundation of Korea (NRF) funded by the Ministry of Education (NRF-2013R1A1A2064673), and the National Research Foundation of Korea (NRF) grant funded by the Korean Government (MSIP) (2008-0062484).

\section{References}

1. Park SY, Yook CS, Nohara T, Mizutani T and Tanaka T: Random amplified polymorphic DNA analysis of genetic relationships among Acanthopanax species. Arch Pharm Res 27: 1270-1274, 2004.

2. Park SY: Studies on RAPD analysis and triterpenoidal constituents of Acanthopanax species. Kumamoto University Press 3: 1-3, 2002.

3. Phuong NT, Lee KA, Jeong SJ, Fu CX, Choi JK, Kim YH and Kang JS: Capillary electrophoretic method for the determination of diterpenoid isomers in Acanthopanax species. J Pharm Biomed Anal 40: 56-61, 2006.
4. Kang JS, Linh PT, Cai XF, Kim HS, Lee JJ and Kim YH: Quantitative determination of eleutheroside B and E from Acanthopanax species by high performance liquid chromatography. Arch Pharm Res 24: 407-411, 2001.

5. Li Z, Kim JH, Liu XQ, Lee KT and Yook CS: Anticancer effects in vitro and chemical compositions of extracts of Acanthopanax henryi. Journal of Acupuncture and Herbs 1: 49-54, 2014.

6. Li Z, Li XJ, Kwon OX, Wang X, Zou QP, Liu XQ and Lee HK: Chemical constituents from leaves of Acanthopanax henryi (II) Nat Prod Sci 21: 196-204, 2015.

7. Lumeng CN and Saltiel AR: Inflammatory links between obesity and metabolic disease. J Clin Invest 121: 2111-2117, 2011

8. Balija TM and Lowry SF: Lipopolysaccharide and sepsis-associated myocardial dysfunction. Cur Opin Infect Dis 24: 248-253, 2011.

9. Peri F, Piazza M, Calabrese V, Damore G and Cighetti R: Exploring the LPS/TLR-4 signal pathway with small molecules. Biochem Soc Trans 38: 1390-1395, 2010.

10. Nathan C: Nitric oxide as a secretory product of mammalian cells. FASEB J 6: 3051-3064, 1992.

11. Zhao L, Weber PA, Smith JR, Comerford ML and Elliott GT: Role of inducible nitric oxide synthase in pharmacological 'preconditioning' with monophosphoryl lipid A. J Mol Cell Cardiol 29: 1567-1576, 1997.

12. Hawkey CJ: COX-2 inhibitors. Lancet 353: 307-314, 1999.

13. Mclnturff JE, Modlin RL and Kim J: The role of toll-like receptors in the pathogenesis and treatment of dermatological disease. J Invest Dermatol 125: 1-8, 2005.

14. Rock FL, Hardiman G, Timans JC, Kastelein RA and Bazan JF: A family of human receptors structurally related to Drosophila Toll. Proc Natl Acad Sci USA 95: 588-593, 1998.

15. Medzhitov R, Preston-Hurlburt P and Janeway CA Jr: A human homologue of the Drosophila Toll protein signals activation of adaptive immunity. Nature 388: 394-397, 1997.

16. Wu J, Zhou J, Chen X, Fortenbery N, Eksioglu EA, Wei S and Dong J: Attenuation of LPS-induced inflammation by ICT, a derivate of icariin, bia inhibition of the CD14/TLR-4 signaling pathway in human monocytes. Int Immunopharmacol 12: 74-79, 2012.

17. Chen CC and Wang JK: p38 but not p44/42 mitogen-activated protein kinase is required for nitric oxide synthase induction mediated by lipopolysaccharide in RAW 264.7 macrophages. Mol Pharmacol 55: 481-488, 1999.

18. Xia Z, Dickens M, Raingeaud J, Davis RJ and Greenberg ME: Opposing effects of ERK and JNK-p38 MAP kinases on apoptosis. Science 270: 1326-1331, 1995.

19. Gilmore TD: Introduction to NF-kappaB: Players, pathways, perspectives. Oncogene 25: 6680-6684, 2006.

20. Brasier AR: The NF-kappaB regulatory network. Cardiovasc Toxicol 6: 111-130, 2006.

21. Perkins ND: Integrating cell-signalling pathways with NF-kappaB and IKK function. Nat Rev Mol Cell Biol 8: 49-62, 2007.

22. Gilmore TD: The Rel/NF-kappaB signal transduction pathway: Introduction. Oncogene 18: 6842-6844, 1999.

23. Tian B and Brasier AR: Identification of a nuclear factor kappa B-dependent gene network. Recent Prog Horm Res 58: 95-130, 2003.

24. Shao CJ, Ryoji Kasai, Xu JD and Tanaka O: Saponins from leaves of Acanthopanax senticosus Harms., Ciwujia: Structures of Ciwujianosides B, $C_{1}, C_{2}, C_{3}, C_{4}, D_{1}, D_{2}$ and E. Chem Pharm Bull 36: 601-608, 1988.

25. Li Z: Simultaneous determination of fifteen triterpenoid saponins in different medicinal parts of Acanthopanax henryi by HPLC-CAD-ESI-MS. In: Study on chemical constituents of Acanthopanax henryi (Oliv.) Harms. Hunan University of Traditional Chinese Medicine, Changsha, pp45-66, 2015 (In Chinese).

26. Livak KJ and Schmittgen TD: Analysis of relative gene expression data using real-time quantitative PCR and the 2(-Delta Delta C(T)) Method. Methods 25: 402-408, 2001.

27. Hou JP and Jin Y: Herbal painkillers: Relief of lingering arthritic pain and rheumatism. In: The Healing Power of Chinese Herbs and Medicinal Recipes. Russo E (ed). Routledge Taylor \& Francis Group, Oxford, pp413-416, 2005.

28. Zhang XD, Li Z, Liu GZ, Wang X, Kwon OK, Lee HK, Whang WK and Liu XQ: Quantitative determination of 15 bioactive triterpenoid saponins in different parts of Acanthopanax henryi by HPLC with charged aerosol detection and confirmation by LC-ESI-TOF-MS. J Sep Sci 39: 2252-2262, 2016. 
29. Jiang W, Li W, Han L, Liu L, Zhang Q, Zhang S, Nikaido T and Koike K: Biologically active triterpenoid saponins from Acanthopanax senticosus. J Nat Prod 69: 1577-1581, 2006.

30. Opal SM and DePalo VA: Anti-inflammatory cytokines. Chest 117: $1162-1172,2000$.

31. McInnes IB and Scheett G: Cytokines in the pathogenesis of rheumatoid arthritis. Nat Rev Immunol 7: 429-442, 2007.

32. Aggarwal BB and Natarajan K: Tumor necrosis factors: Developments during the last decade. Eur Cytokine Netw 7: 93-124, 1996.

33. Brennan FM and McInnes IB: Ebidence that cytokines play a role in rheumatoid arthritis. J Clin Invest 118: 3537-3545, 2008.

34. Jun CD, Choi BM, Kim HM and Chung HT: Involvement of protein kinase $\mathrm{C}$ during taxol-induced activation of murine peritoneal macrophages. J Immunol 154: 6541-6547, 1995.

35. Green SJ, Mellouk S, Hoffman SL, Meltzer MS and Nacy CA Cellular mechanisms of nonspecific immunity to intracellular infection: Cytokine-induced synthesis of toxic nitrogen oxides from L-arginine by macrophages and hepatocytes. Immunol Lett 25: 15-19, 1990

36. Gorczyniski RM and Stanely J (eds): Clinical Immunology. Landes Bioscience. Austin, TX, 1999.

37. Green SJ, Nacy CA, Schreiber RD, Granger DL, Crawford RM, Meltzer MS and Fortier AH: Neutralization of gamma interferon and tumor necrosis factor alpha blocks in vivo synthesis of nitrogen oxides from $\mathrm{L}$-arginine and protection against Francisella tularensis infection in Mycobacterium bovis BCG-treated mice. Infect Immun 61: 689-698, 1993.

38. Kamijo R, Gerecitano J, Shapiro D, Green SJ, Aguet M, Le J and Vilcek J: Generation of nitric oxide and clearance of interferon-gamma after BCG infection are impaired in mice that lack the interferon-gamma receptor. J Inflamm 46: 23-31, 1995.

39. Green SJ, Scheller LF, Marletta MA, Seguin MC, Klotz FW, Slayter M, Nelson BJ and Nacy CA: Nitric oxide: Cytokine-regulation of nitric oxide in host resistance to intracellular pathogens. Immunol Lett 43: 87-94, 1994.
40. Koeberle A and Werz O: Microsomal prostaglandin E2 synthase-1. In: Anti-inflammatory Drug Discovery. Levin JI and Laufer S (eds). Royal Society of Chemistry Publishing, Cambridge, pp8-12, 2012.

41. Pearson G, Robinson F, Beers Gibson T, Xu BE, Karandikar M, Berman K and Cobb MH: Mitogen-activated protein (MAP) kinase pathways: Regulation and physiological functions. Endocr Rev 22: 153-183, 2001.

42. Nishida E and Gotoh Y: The MAP kinase cascade is essential for diverse signal transduction pathways. Trends Biochem Sci 18: 128-131, 1993.

43. Kirkwood KL and Rossa C Jr: The potential of p38 MAPK inhibitors to modulate periodontal infections. Curr Drug Metab 10: 55-67, 2009.

44. Kaminska B: MAPK signaling pathways as molecular targets for anti-inflammatory therapy-from molecular mechanisms to therapeutic benefits. Biochim Biophys Acta 1754: 253-262, 2005.

45. Surh YJ, Chun KS, Cha HH, Han SS, Keum YS, Park KK and Lee SS: Molecular mechanisms underlying chemopreventive activities of anti-inflammatory phytochemicals: Down-regulation of COX-2 and iNOS through suppression of NF-kappa B activation. Mutat Res 480-481: 243-268, 2001.

46. Makarov SS: NF-kappaB as a therapeutic target in chronic inflammation: Recent advances. Mol Med Today 6: 441-448, 2000.

47. Tian L, Zhou DS, Wang KZ, Zhang W, Shi ZB, Fan LH and Sun S: Association of toll-like receptor 4 signaling pathway with steroid-induced femoral head osteonecrosis in rats. J Huazhong Univ Sci Technolog Med Sci 34: 679-686, 2014

48. Kang OH, Chae HS, Choi JG, Oh YC, Lee YS, Kim JH, Seung MJ, Jang HJ, Bae KH, Lee JH, et al: Ent-pimara-8(14), 15-dien-19-oic acid isolated from the roots of Aralia cordata inhibits induction of inflammatory mediators by blocking NF-kappaB activation and mitogen-activated protein kinase pathways. Eur J Pharmacol 601: 179-185, 2008. 